\title{
Detection of Toxoplasma gondii in environmental matrices (water, soil, fruits and vegetables)
}

\author{
Adeela Ajmal ${ }^{1}$, Azhar Maqbool ${ }^{1}$, Muhammad Fiaz Qamar ${ }^{2 \star}$, Kamran Ashraf ${ }^{1}$ and Aftab Ahmad \\ Anjum ${ }^{1}$ \\ ${ }^{1}$ University of Veterinary and Animal Sciences, Lahore, Pakistan. \\ ${ }^{2}$ Department of Zoology, GC University, Lahore, Pakistan.
}

Accepted 29 March, 2013

\begin{abstract}
Toxoplasmosis is a widely distributed protozoan disease caused by Toxoplasma gondii. The infective stages of $T$. gondii are capable of infecting a variety of vertebrates including humans. Domestic and wild felids are capable of serving as definitive hosts and $T$. gondii oocysts are excreted in their faeces. Toxoplasmosis is caused by ingesting $T$. gondii oocysts from contaminated water or foodstuff or by consuming T. gondii tissue cysts from infected hosts. However, the impact of oocysts on toxoplasmosis epidemiology needs to be specified because they are suspected to be associated with $T$. gondii seroprevalence in some emerging outbreaks of acute toxoplasmosis in humans from soil or water. They are probably responsible for a significant part of infections in animals that could be later consumed by humans. Detection of $T$. gondii oocysts in environmental samples is great challenge as this coccidian parasite can be responsible for severe infections in humans and animals via ingestion of a single oocyst from contaminated water, soil, fruits or vegetables. The present study was designed to develop methods for the detection of oocysts from water, soil and food. The highest prevalence was reported from water around farms (13\%) followed by lakes and pools (9\%) and water reservoirs $(7 \%)$. The lowest rates resulted from drinking water and tubewells (6\% each). Overall prevalence of $T$. gondii contamination was higher in vegetables $(5.6 \%)$ than fruits $(4 \%)$. The highest prevalence of $T$. gondii contamination was noted in gardens and backyards of homes and gardens, that is, 20 and $20 \%$, respectively. In these places, cats often defecate and become a source of infection. Then followed by public enclosures where infection was $14.3 \%$. The lowest (13.3\%) contamination was noted in homes of urban areas. T. gondii infection in rural areas was the highest $(20 \%)$ in home back yards followed by homes $(16.7 \%)$ then public enclosure $(14.5 \%)$ whereas the lowest $(13.3 \%)$ at gardens of rural areas.
\end{abstract}

Key words: Toxoplasmosis, Toxoplasma gondii, detection, water, foodstuff.

\section{INTRODUCTION}

Toxoplasmosis caused by Toxoplasma gondii is a protozoan disease capable of infecting a variety of animal species and humans (Dubey and Jones, 2008). Domestic and wild felids are capable of serving as definitive hosts, shedding $T$. gondii oocysts in their faeces. All warm blooded animals, including humans can potentially serve as intermediate hosts, harbouring $T$. gondii in the form of tissue cysts. Generally, infection causes only mild clinical disease in humans and sero surveys throughout the world suggest that approximately $30 \%$ of the human population has been exposed to this (Dubey and Beattie, 1988). Serious clinical disease occasionally occurs when organisms cross the placenta in women and infect the foetus in immunocompromised individuals, particularly AIDS patients and rarely in immunocompetent individuals leading to a variety of syndromes including neuroretinitis 
and encephalitis. It is because of these sequels that toxoplasmosis is a serious public health concern. People acquire toxoplasmosis postnatally by ingesting $T$. gondii oocysts from contaminated environments or by consuming $T$. gondii tissue cysts in inadequately prepared meat products (Dubey and Beattie, 1988), raw meat containing tissue cysts or by ingestion of resistant oocysts from environmental matrices. The diferent transmission routes of toxoplasmosis are still undetermined, since it is not yet possible using serological investigations to discriminate infections due to oocysts from those induced by cysts. However, the impact of oocysts on toxoplasmosis epidemiology needs to be specified because they are suspected to be associated with $T$. gondii seroprevalence in some emerging outbreaks of acute toxoplasmosis in humans from soil or water (Teutsch, 1979; Stagno, 1980; Bowie et al., 1997); they are probably responsible for a significant part of infections in animals that could be later consumed by humans (Tenter et al., 2002).

The organism $T$. gondii is an obligate intracellular protozoan that belongs to the phylum Apicomplexa, subclass coccidia. It can take several different forms: the oocyst; the tachyzoite; and the tissue cyst. Thus, the number of oocysts which may be found in random environmental samples is probably low. Human beings can be infected with $T$. gondii by ingestion or handling undercooked or raw meat (mainly pork and lamb) containing tissue cysts or cat faecal infected water or food. Most individuals are infected inadvertently, thus the specific route of transmission cannot usually be established. Variations in seroprevalence of $T$. gondii seem to correlate with eating and hygiene habits of a population. $T$. gondii can also be transmitted via blood or leucocytes from immunocompetent and immunocompromised donors. Twenty two to twenty three infections in laboratory personnel have arisen by contact with contaminated needles and glassware or infected animals, (Iqbal and Khalid, 2007). In twenty four to twenty five congenital transmissions after maternal acquisition of $T$. gondii for the first time during gestation, the parasite enters the fetal circulation by infecting the placenta (Remington et al., 1990). The birth prevalence of congenital toxoplasmosis ranges from one to ten per 10,000 live births. Twenty six to twenty eight maternal infections acquired before gestation poses little or no risk to the fetus except in women who become infected a few months (at the most, 3) before conception (Wallon et al., 1999). Frequency of congenital transmission varies considerably according to the time of gestation that the mother became infected. The overall frequency of subclinical infection in newborns with congenital toxoplasmosis is as high as $85 \%$.

This finding lends support to the contention that the oral route is the major source of infection. Several outbreaks of toxoplasmosis in human beings have been linked epidemiologically to drinking of unfiltered water (Bowie et al., 1997). Detection of $T$. gondii oocysts in environmental samples is a great challenge to researchers as this cocci- dian parasite can be responsible for severe infec-tions in humans and animals via ingestion of a single oocyst from contaminated water, soil, fruits or vegetables. Despite field investigations, oocysts have been rarely recovered from the environment due to lack of sensitive methods. Therefore, development of detection methods was designed as described by Mizgajska-Wiktor (2005) for sampling; Dubey et al. (1995) for DNA extraction and PCR. Specific and sensitive methods exist but they need to be improved for $T$. gondii oocysts. The study design of the present proposed study has been selected for suitable detection of oocysts from water, soil, food and parks environment. This study will help in the detection of $T$. gondii in drinking water, recreational irrigation waters, fruits and vegetables.

\section{MATERIALS AND METHODS}

\section{Collection of soil samples}

Five hundred soil samples were collected at different sites located in the two cities of Multan and Ali Pur. The samples were taken from places where cats often excrete $T$. gondii oocysts. Sand pits playgrounds, parks (where children often play) as well as "farming ground (grassland and agricultural landscape)" and areas around rubbish dumps were examined. Samples were obtained according to the following procedure: $300 \mathrm{~g}$ of the soil were taken from the surface layer of the ground (the depth of 2 to $5 \mathrm{~cm}$ ), dried at room temperature for 2 days, and then sieved (Mizgajska-Wiktor, 2005). Finally, $40 \mathrm{~g}$ of the soil prepared in this way were taken for further examinations.

\section{Concentration technique}

Concentration technique was used to detect $T$. gondii oocysts in naturally contaminated water. This method was developed under laboratory conditions to detect water borne protozoa. For this purpose, tap water having high number of oocysts was used. The recovery procedure included the concentration of 50 to 1000 oocysts per litre by flocculation or filtration, purification and detection of oocysts as described by Dubey et al. (1988).

\section{DNA extraction}

DNA extraction was performed as described by Dubey et al. (1995). For specific $T$. gondii detection, PCR reaction was performed by the use of a primer set described by Dubey et al. (1995).

\section{Microscopic detection}

For the detection of oocysts in highly contaminated samples, light microscopy was used. For the detection of unsporulated and sporulated oocysts, epifluorescence technique with uv light was used (excitation filter 330 to $385 \mathrm{~nm}$, dichroic mirror $400 \mathrm{~nm}$, barrier filter $420 \mathrm{~nm}$ ). This facilitated the detection because both unsporulated and sporulated oocysts exhibit typical blue auto fluorescence.

\section{RESULTS AND DISCUSSION}

\section{Detection of $T$. gondii in water}

The results of recovery test showed the highest (13\%) 
Table 1. Detection of $T$. gondii in water samples by PCR on the basis of B1 and REP genes.

\begin{tabular}{lcccc}
\hline \multirow{2}{*}{ Type of water sample } & \multirow{2}{*}{ Number of sample } & \multicolumn{2}{c}{ Number of positive samples by PCR } & \multirow{2}{*}{ Positive (\%) } \\
\cline { 3 - 4 } & & B1 & 6 & 6 \\
Drinking water from municipality & 100 & 9 & 9 & 9 \\
Lakes and Pools & 100 & 7 & 7 & 7 \\
Water reservoirs & 100 & 13 & 12 & 13 \\
Around Farms & 100 & 6 & 6 & 6 \\
Tube wells & 100 & &
\end{tabular}

Table 2. Detection of $T$. gondii in fruits and vegetables samples by PCR on the basis of B1 and REP genes.

\begin{tabular}{lcccc}
\hline \multirow{2}{*}{ Type of sample } & \multirow{2}{*}{ Number of sample collected } & \multicolumn{2}{c}{ Number of positive samples by PCR } & \multirow{2}{*}{ Percentage of infection (\%) } \\
\cline { 3 - 5 } & 125 & 5 & 5 & REP \\
Fruits & 125 & 7 & 7 & 5.6 \\
Vegetables & & & & 4 \\
\hline
\end{tabular}

prevalence in water around farms followed by lakes and pools $(9 \%)$ then water reservoirs $(7 \%)$, whereas the lowest was in drinking water and tube wells (6 and $6 \%$, respectively) (Table 1, Figure 1).

\section{Detection of $T$. gondii in samples of fruits and vegetables}

A total of 250 samples of fruits and vegetables were collected for detection of $T$. gondii. The fruits included are apple, banana and guava. And the vegetables included are cabbage, brinjal and tomato. From the results shown in Table 2, it was noted that overall prevalence of $T$. gondii infection was higher in vegetables $(5.6 \%)$ than fruits (4\%). It was also noted that fruit shop keepers washed their fruits with clean water, whereas vegetables were often washed with lake/stream water. So, infection was higher in vegetables than fruits (Figure 2).

\section{Detection of $T$. gondii in samples of fruits and vegetables before and after rain fall}

Out of the 250 samples of fruits $(n=125)$ and vegetables $(n=125), 90$ samples of vegetables were collected before rainfall and 35 after rainfall, whereas out of 125 fruit samples, 86 were collected before rainfall and 39 were collected after rain fall (Figure 2).

\section{Detection of T. gondii in samples of fruits}

From the results, it was shown that contamination was higher in fruits after rainfall $(5.13 \%)$ than before rainfall (3.48\%). The overall infection in fruits was $4 \%$ (Figure 3 ).

\section{Detection of $T$. gondii in samples of vegetables}

A total of 72 samples were collected from vegetables before rainfall, out of these $4.16 \%$ were found positive, whereas out of the 53 samples collected after rainfall, 4 were found positive. Contamination rate was thus $7.55 \%$ (Figure 4).

\section{Detection of $T$. gondii in soil samples}

A total of 250 soil samples were collected from urban $(n=$ $125)$ and rural $(n=125)$ areas. The results are presented in Tables 3 and 4 . The highest prevalence of $T$. gondii contamination was noted in gardens and backyards of homes and gardens (20 and $20 \%$, respectively). In these places, cats often defecate and become a source of infection. Then followed by public enclosures where contamination was $14.3 \%$. The lowest contamination (13.3\%) was noted at homes of urban areas. Contamination in rural areas was the highest $(20 \%)$, followed by contamination in home backyards, homes (16.7\%) and public enclosure $(14.5 \%)$, whereas the lowest $(13.3 \%)$ was at gardens of rural areas Tables 5 and 6, Figures 5 and 6).

\section{DISCUSSION}

Information available on the prevalence of $T$. gondii oocysts in the environment are rare (Villena et al., 2004; Sroka et al., 2006; Vaudaux et al., 2012; Du et al., 2011; Nimir et al., 2011). Some of the experiments were performed under laboratory conditions (tap water, contaminated with high number of oocysts) that were far from those usually occurring in natural samples (Kourenti et al., 2003; Villena et al., 2004). Very little information is available on the presence of $T$. gondii oocysts in naturally contaminated water (Villena et al., 2004; De Moura et al., 2006; Sroka et al., 2006). However, soil is also an environmental source of Toxoplasmosis in humans (Teutsch et al., 1979; Stagno et al., 1980; Weigel et al., 1999). It was indicated that pregnant women mostly get infection from soil (Cook et al., 2002). It was noted that oocysts 
Table 3. Detection of $T$. gondii in fruits samples by PCR on the basis of B1 and REP gene.

\begin{tabular}{lcccc}
\hline \multirow{2}{*}{ Types of sample } & \multirow{2}{*}{ Number of sample collected } & \multicolumn{2}{c}{ Number of positive samples by PCR } & \multirow{2}{*}{ Percentage of contamination (\%) } \\
\cline { 3 - 4 } & & B1 & REP & 3 \\
Before rainfall & 86 & 3 & 2 & 5.48 \\
After rainfall & 39 & 2 & 5 & 4 \\
Total & 125 & 5 & 2 & 4 \\
\hline
\end{tabular}

Table 4. Detection of $T$. gondii in vegetables samples by PCR on the basis of B1 and REP gene.

\begin{tabular}{|c|c|c|c|c|}
\hline \multirow{2}{*}{ Types of sample } & \multirow{2}{*}{ Number of sample collected } & \multicolumn{2}{|c|}{ Number of positive samples by PCR } & \multirow{2}{*}{ Percentage of contamination (\%) } \\
\hline & & B1 & REP & \\
\hline Before rainfall & 72 & 3 & 3 & 4.16 \\
\hline After rainfall & 53 & 4 & 4 & 7.55 \\
\hline Overall & 125 & 7 & 7 & 5.6 \\
\hline
\end{tabular}

Table 5. Detection of $T$. gondii in soil samples of urban area through PCR on the basis of B1 and REP gene.

\begin{tabular}{lcccc}
\hline \multirow{2}{*}{ Source of sample } & \multirow{2}{*}{ Number of sample } & \multicolumn{2}{c}{ Number of positive samples by PCR } & \\
\cline { 3 - 4 } & & B1 & REP & Percentage of contamination (\%) \\
\hline Homes & 30 & 4 & 4 & 13.3 \\
Gardens & 30 & 6 & 6 & 20 \\
Public enclosures & 35 & 5 & 6 & 14.3 \\
Back yards & 30 & 6 & 6 & 20 \\
\hline
\end{tabular}

Table 6. Detection of Toxoplasma in soil samples of rural area by PCR on the basis of B1 and REP gene.

\begin{tabular}{lcccc}
\hline \multirow{2}{*}{ Source of sample } & \multirow{2}{*}{ Number of sample } & \multicolumn{2}{c}{ Number of positive samples by PCR } & \multirow{2}{*}{ Percentage of contamination (\%) } \\
\cline { 3 - 5 } & 30 & 5 & 5 & 16.7 \\
Homes & 30 & 4 & 4 & 13.3 \\
Gardens & 35 & 5 & 5 & 14.5 \\
Public enclosures & 30 & 6 & 6 & 20 \\
Back yards & & &
\end{tabular}



Figure 1. Detection of Toxoplasma gondii in water samples by PCR on the basis of B1 and REP gene.

may remain infective in soil for many months to a year (citation missing). The results of the present study indicated that soil may play an important role in the epidemio- logy of Toxoplasmosis. The presence of $T$. gondii DNA in the examined soil samples clearly indicates that sand pits contaminated with oocysts may be a source of infection 


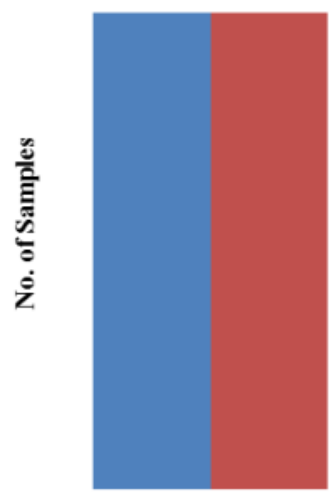

m Fruits $\quad$ Vegetables

Figure 2. Detection of $T$. gondii in fruits and vegetables samples by PCR on the basis of B1 and REP gene.

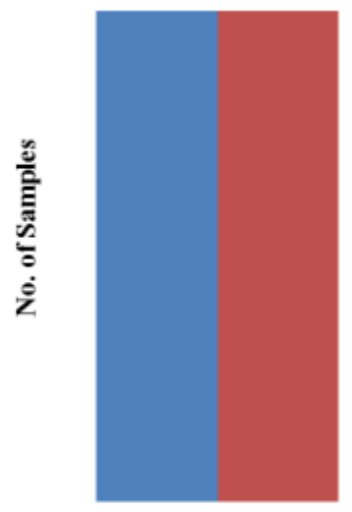

$$
=\text { Fruits } \quad \text { Vegetables }
$$

Figure 3. Detection of T. gondii in fruits samples through PCR on the basis of B1 and REP gene.

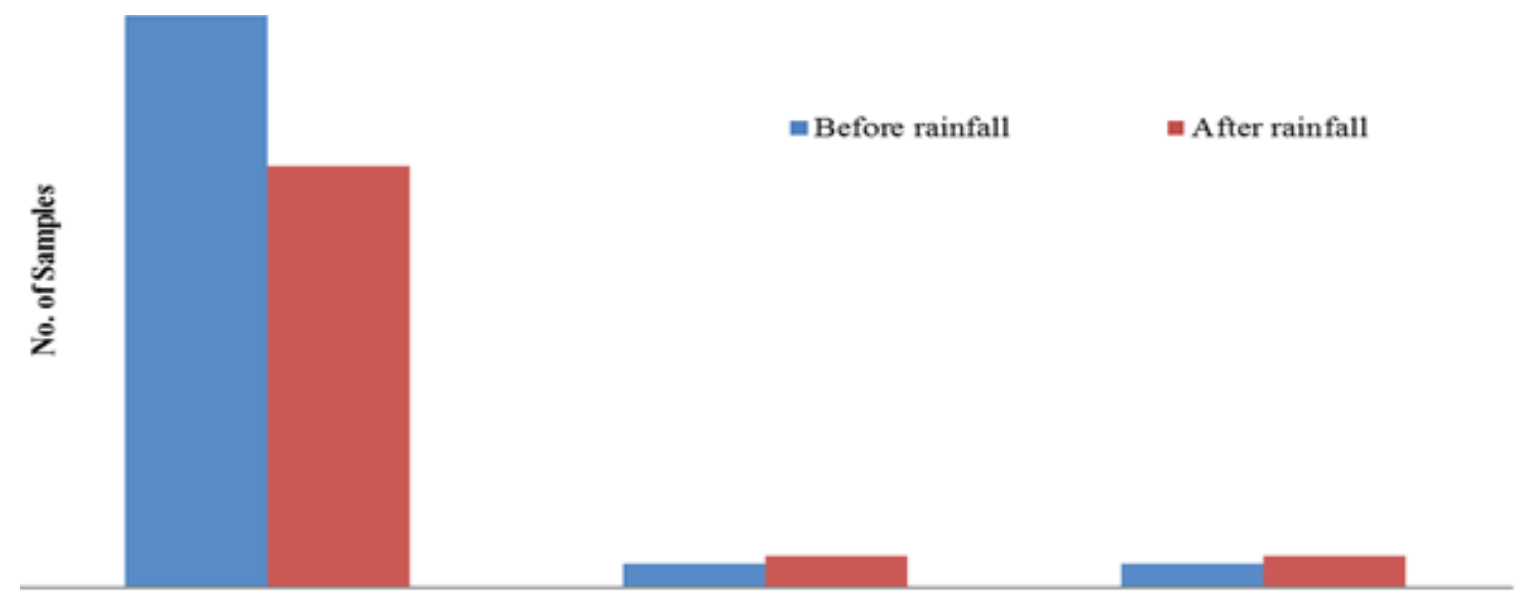

Figure 4. Detection of $T$. gondii in vegetables samples by PCR on the basis of B1 and REP gene.

for humans.

It was also noted that the frequency of the detection of T. gondii DNA in soil is similar to Toxocara and Ancylostoma eggs from the soil (Urquhart et al., 1991). It is also noted that a large number of sand pits were contaminated with T. gondii oocysts. Children playing in dirty sand are likely to swallow by accident, the oocysts of $T$. gondi which may be found in the soil pits which is a danger for 


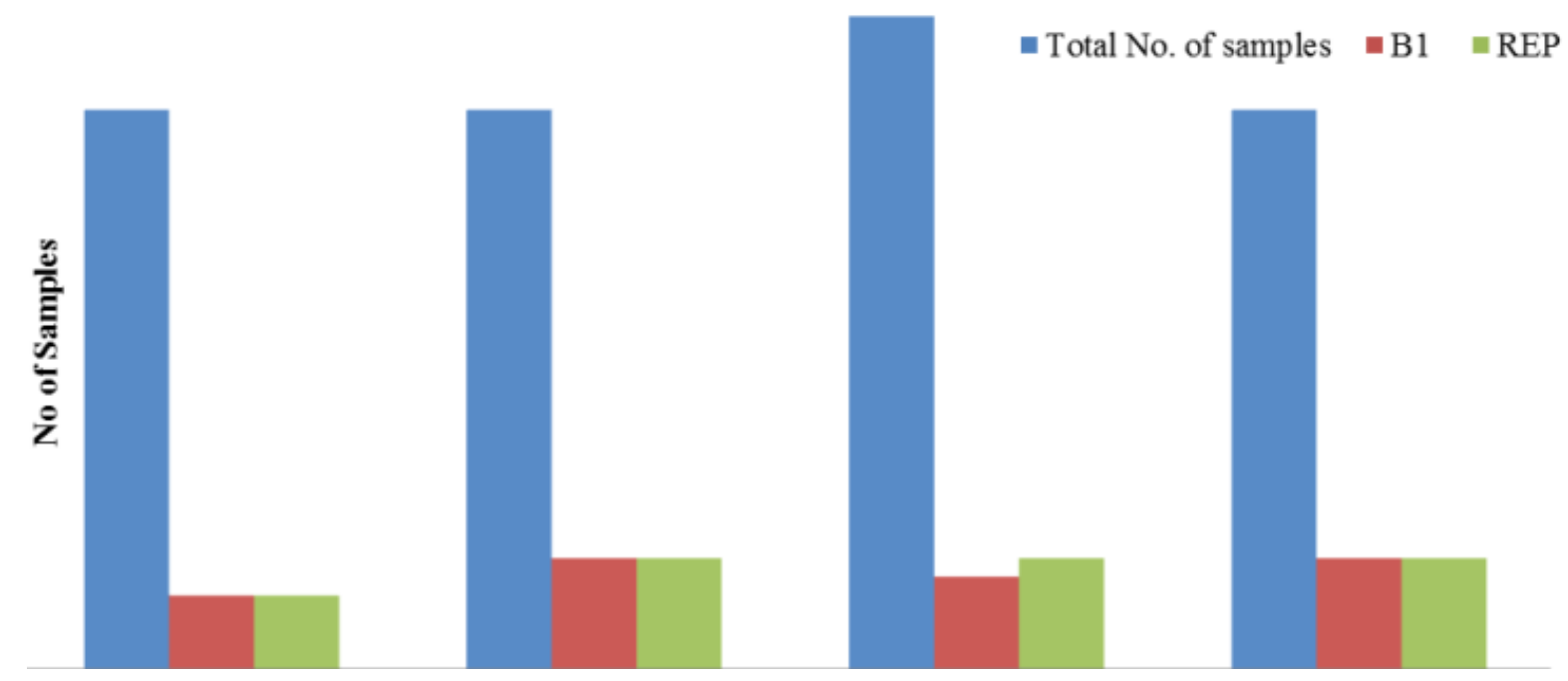

Figure 5. Detection of $T$. gondii in soil samples of urban area by PCR on the basis of B1 and REP gene.

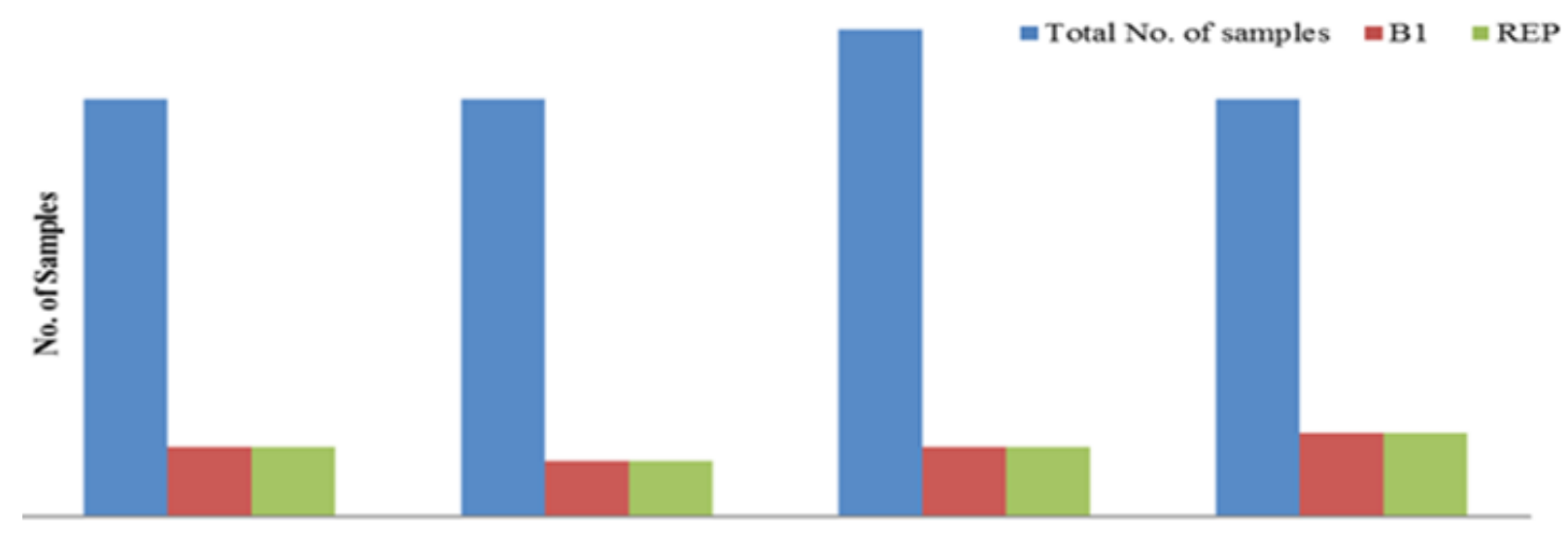

Figure 6. Detection of Toxoplasma in soil samples of rural area by PCR on the basis of B1 and REP gene.

children and adults. There is a need for better protection of such places from cat's faeces. This can be done by systematic changing of the sand and lack of access for animals. Sand pits are the common places of cat defecation, it can also contribute to $T$. gondii parasite spreading in the environment by wind, storm water and invertebrates. Due to excretion of feral cats, areas near rubbish dumps or sand heaps can also be contaminated with $T$. gondii oocysts. It was also noted that the distribution of areas contaminated by oocysts was highly heterogenous in an urban environment (Afonso et al., 2006). Maximum contamination was found at the defecation sites of cats.

It was noted that proximity of cats to humans for deposition of cat faeces in urban areas may increase the possibility of contamination with oocysts. In rural areas, oocysts may be shed far from houses. It may be difficult to find faeces because they are quickly disintegrated under natural conditions and felids bury them. In soil, oocyst persist at the surface or up to $10 \mathrm{~cm}$ depth but their transport through soil is not known. However, oocyst retention increases with the use of filter columns (Bradford and Bettahar, 2005). In water, they may be found more likely at the bottom due to their specific gravity (Dubey et al., 1970). Fruits and vegetables contamination by oocysts are by direct exposure to cat faeces or irrigation with contaminated water. Due to oocysts prevalence and to the possibility for cats to be infected at any season during the years, no seasonal occurance of oocysts is expected in most cats. However, environmental matrices may be more heavily contaminated by soil washing after peaks in rainfall (Bowie et al., 1997). Toxoplasma oocysts are spread in the environment mainly via wind, water, manure and by earthworms and arthropods. They can contaminate surface water, soil, harvest feeds, fruits and vegetables (Dubey and Beattie, 1988; Dubey et al., 1970). They have been recovered from naturally contaminated soil and water. Their sporulated oocysts can remain infective in water for 54 months at $4^{\circ} \mathrm{C}$ and 18 months in soil at various range of temperature.

The present study will be helpful in studying the occur- 
rence, prevalence and viability of $T$. gondii oocysts in environment matrices and specify sources of animal and human contamination. In the present study, 500 water samples were collected from various sources: drinking water from municipality, lakes, pools, various reservoirs around farms and from tube wells. The highest (13\%) prevalence was reported from water around farms followed by lakes and pools (9\%) then water reservoirs $(7 \%)$, whereas the lowest (6\% each) from municipality drinking water and tube wells. Almost similar results were reported by Kourenti et al. (2003) and Villena et al. (2004).

\section{REFERENCES}

Afonso E, Lemoine M, Poulle M, Ravat M, Romand S, Thulliez P, Villena I, Aubert D, Rabilloud M, Riche B, Gilot-Fromont E (2006). Spatial distribution of soil contamination by Toxoplasma gondii in relation to cat defecation behavior in an urban area. Int. J. Parasitol. 38:1017-1023.

Bowie WR, King AS, Werker DH, Isaac-Renton JL, Bell A, Eng SBV, Marion SA (1997). Outbreak of toxoplasmosis associated with municipal drinking water. Lancet, 350, 173-177.

Bradford SA, Bettahar M (2005). Straining, attachment, and detachment of cryptosporidium oocysts in saturated porous media. J. Environ. Qual. 34(2): 469-478.

Cook AJC, Gilbert RE, Buffolano W, Zufferey J, Petersen E, Jenum PA, Foulon W, Semprini AE, Dunn DT (2002). Sources of toxoplasma infection in pregnant women: European multicentre case-control studyCommentary: Congenital toxoplasmosis-further thought for food BMJ 321:142

De Moura L, Bahia-Oliveira LMG, Wada MY, Jones JL, Tuboi SH, Caramo EH, Ramalho WM, Camargo NL, Trevisan R, Graca RMT, da Silva AJ, Moura L, Dubey JP, Garrett DO (2006). Waterborne toxoplasmosis, Brasil: from field to gene. Emerg Infect Dis 12:326329

Dubey JP, Beattie CP (1988). Toxoplasmosis of Animals and Man. CRC Press Inc., Boca Raton 1988.

Dubey JP, Jones JL (2008). Toxoplasma gondii infection in humans and animals in the United States. Int. J. Paras. 38:1257-1278.

Iqbal J, Khalid N (2007). Detection of acute Toxoplasma gondii infection in early pregnancy by $\mathrm{lgG}$ avidity and PCR analysis. J Med Microbiol. 56(11):1495-9
Kourenti C, Heckeroth A, Tenter A Karanis P (2003). Development and application of different methods for the detection of Toxoplasma gondii in water. Appl Environ. Microbiol. 69: 102-106.

Mizgajska-Wikto $H$ (2005). Recommended method for recovery of Toxocara and other geohelminth eggs from soil. Wiad. Parazytol. $51: 21-22$

Remington JS, Desmonts G (1990). Toxoplasmosis. In: Remington JS, Klein JO, editors. Infectious diseases of the fetus and newborn infant. 3. Philadelphia: WB Saunders;. pp. 89-195.

Sroka J, Wojcik-Fatla A, Dutkiewicz J (2006). Occurence of Toxoplasma gondii in water from wells located on farms. Ann. Agric. Environ. Med. 13:169-175

Stagno S, Dykes AC, Amos CS, Head RA, Juranek DD, Walls K (1980). An outbreak of toxoplasmosis linked to cats. Pediatrics 65:706-711

Teutsch SM, Juranek DD, Sulzer A, Dubey JP, Sikes RK (1979). Epidemic toxoplasmosis associated with infected cats. N Engl. J. Med. 300:695-699

Tenter Astrid M, John R, Barta IB, Donald WD, Heinz M, David AM, Andrew RC, Thompson, Patricia, Conrad A (2002). The conceptual basis for a new classification of the coccidian. Int. J. Parasitol. 32: 595-616.

Urquhart GM, Armour J, Duncan JL, Dunn AM, Jennings FW (1991). Parasitologia Veterinária. Rio De Janeiro: Guanabara Koogan, p. 306.

Villena I, Aubert D, Gomis P, Ferté HH, Inglard JCH, Denis-Bisiaux $\mathrm{H}$, Dondon JM, Pisano E, Ortis N, Pinon JM (2004). Evaluation of a strategy for Toxoplasma gondii oocyst detection in water. Appl. Environ. Microbiol. 70:4035-4039.

Wallon M, Liou C, Garner P, Peyron F (1999). Congenital toxoplasmosis: systematic review of evidence of efficacy of treatment in pregnancy. BMJ 318: 1511-1514.

Weigel RM, Dubey JP, Dyer D, Siegel AM (1999). Risk factors for infection with Toxoplasma gondii for residents and workers on swine farms in Illinois. Am. J. Trop. Med. Hyg. 60: 793-798. 